British Journal of Environmental Sciences

Vol.10, No.2, pp. 41-50, 2022

Print ISSN: 2054-6351 (print),

Online ISSN: 2054-636X (online)

\title{
AN EVALUATION OF CURRENT QUALITY ASSESSMENT METHODS AND APPROACHES BY BUILDING CONTRACTORS IN LAGOS STATE, NIGERIA
}

\author{
Ngozi Marykate Okoye, Kevin Chuks Okolie,Okechukwu Chiamaka Ogochukwu
}

Department of Building, Nnamdi Azikiwe University, Awka-Anmabra State

\begin{abstract}
Citation: Ngozi Marykate Okoye, Kevin Chuks Okolie,Okechukwu Chiamaka Ogochukwu (2022) An Evaluation of Current Quality Assessment Methods and Approaches by Building Contractors in Lagos State, Nigeria, British Journal of Environmental Sciences, Vol.10, No.2, pp. 41-50
\end{abstract}

\begin{abstract}
Contractors need to pay close attention to the quality of materials used for construction as well as the level of skills of individuals engaging in the building process. Greedy investors are taking advantage of the fact that there are no strict and standardized procedures to monitor and control the construction of new houses or the renovation of existing ones, the need to check the existing quality assessment methods and Approaches Utilised by Building Contractors comes highly. The aim of this study to evaluate current quality assessment methods and approaches by building contractors in Lagos state, Nigeria,. In order to realize this aim, the study examined the various methods like statistical method, visual method,feedback method, use of record and automated method. The study employed a descriptive case study design where data was collected from senior managers, project managers, engineers, architects, quantity surveyors, and technical managers working with building construction companies in the Lagos Metropolitan Area using the mixed method approach. Quantitative data was collected using questionnaire from 109 randomly selected participants and analysed using descriptive and inferential statistics. Qualitative data was collected through interviews with 9 purposively selected respondents and analysed using the thematic analysis technique. The study identified the earlier mention four(4) current quality Assessment Methods and Approaches Utilised by Building Contractors in Lagos State. The findings identified observation/ physical inspections were the most widely applied method of quality assessment while other method is review of records, Feedback and Sampling. The study concludes that developing a model for guiding the process of assessing quality among Lagos and Nigerian contractors. The model helps to standardize the processes of assessing quality within the Lagos construction industry.
\end{abstract}

KEYWORDS: quality assessment methods, quality attributes, construction industry, contractor

\section{INTRODUCTION}

Brown (2015) believes that increases in population, rural to urban migration and the rising economic standings of most Lagos has expanded the demand for affordable and appropriate housing especially in cities experiencing fast growth. For this reason, contractors need to pay close attention to the quality of materials used for construction as well as the level of skills of individuals engaging in the building process. Greedy investors are taking advantage of the fact that there are

ECRTD-UK https://www.eajournals.org/ 
no strict and standardized procedures to monitor and control the construction of new houses or the renovation of existing ones (Brown, 2015). Land owners in major cities such as Lagos are taking advantage of the rise in demand for housing to construct poor quality houses since people are willing to pay whatever amount for the available living units. With a reliable quality assessment system for buildings and other construction projects, it would be easier to monitor the construction process and to determine that individuals adhere to existing standards to guarantee quality of buildings. When contractors abide by the rules and requirements of a certain standardized quality system, the end products of construction projects would be safe buildings for human habitation and would have less negative impacts on the environment (Dubois \& Gadde, 2002). Although abiding by such rules could have increased financial ramifications in the short run, they would have important contribution in saving lives and reducing construction costs. For instance, buildings that collapse when it reaches the fifth floor would have to be rebuilt and this means that all the financial resources expended to this point would go to waste. Structures built following strict quality procedures also last longer resulting in long term cost savings especially in terms of maintenance. Ajayi and Thwal (2015) recognize that implementing a quality assessment system reduces the chances of experiencing poor workmanship, negative environmental impacts and exceeding costs. Implementers of such systems may be met with financial challenges, lack of collaboration and corporation from other players, time constraints and other challenges. For continued success, such challenges need addressing early so that they do not affect the progress.

\section{Purpose of the Research}

The need for monitoring and evaluating any existing methods or approach in managing the result of any system cannot be over-emphasised; as it provides a mirror for improving or making a necessary u-turn on what's working or not. The various existing quality assessment methods and approaches by building contractors have their merit and peculiarities; worthy of note is evaluating them as a standard metrics for making judgements. There have been a gap in having a yardstick for evaluating existing quality assessment methods and approaches The strong implication of the study is its providing a standard metric or framework in selecting appropriate quality assessment methods and approaches as well as helping building contractors in Lagos state, Nigeria and world over to evaluate current quality assessment methods and approaches .

\section{LITERATURE REVIEW}

Just like quality, quality assessment (QA) is quite an ambiguous term that has attracted varying description from different scholars. Ahmad, Sabli, and Othma (2014) described QA as a systematic, data-guided activities that seek to bring about immediate improvements to a given process or product. Szczerban (2002) defined it as the process of systematically monitoring and evaluating various aspects of a given project, service, or product with the aim of ensuring that quality standards are being met. It entails examination of quality parameters vis-à-vis the set standards. Ashokkumar (2014) defined quality assessment as the process of collecting evidence and making inferences on whether quality standards have been attained. He further defined a quality assessment system as a coordinated set of policies, procedures, materials, and tools

ECRTD-UK https://www.eajournals.org/

Journal level DOI: https://doi.org/10.37745/bjes.2013 
designed to ensure that the assessment process is consistent, credible and valid. Quality assessment is a vital component of quality management as it provides organization with data regarding the extent to which work processes and products conform to standards (Harrison, 2005). It gives the organization crucial information that enables it to control key processes and reduce variation in quality.Quality assessment cannot be effective without the application of reliable and valid methods of data collection and analysis. Quality assessment methods used in the construction industry can be divided into three categories; statistical methods, visual methods, and feedback/ questioning methods.

\section{Statistical Methods}

Statistical methods are assessment technique that focuses on the use of quantitative data and approaches of analysis (Mancill \& Thompson, 2012). Statistical methods have a high degree of accuracy because they tend to eliminate bias. They are also more thorough as statistical techniques are used to analyze data. However, these methods require more time and monetary resources to implement. The methods are also complex; hence, require technical skills. Work sampling is one of the statistical techniques that are widely used to measure performance.This technique entails evaluating the amount of productive, non-productive, and supportive time that workers spent in the work station (Kumar, Kumar, Myneni, \& Charan, 2014). According to Pradeepkumar and Loganathan (2015), work sampling is an observational technique where the observer walks through the job site and record information regarding the work in progress. The technique considers each individual worker as a sample and requires the observer to document what the worker is doing based on predetermined work categories. The observation tours are usually random and may being at any point in the work site so as to make it difficult for workers to anticipate. The observation goes on for several days until the right number of sample is obtained (Goso \& Imoto, 2011). A large number of observations are usually required to provide an accurate view of the productivity of the workforce. This technique helps to establish labor productivity and trends that affect it. Orth, Welty, and Jenkins (2006) argue that work sampling is a valuable tool in the construction setting because labor productivity has a major impact on projects' completion time and costs. A significant advantage of this technique is that it measures the work process rather than outcome; hence, it can lead to improvements that have an immediate impact on performance. Work sampling also require relatively little time than other types of studies.

In their study exploring labor management techniques used by building contractors in the Zimbabwe construction industry, Moyo, Mangore, and Chigara (2014) found work sampling technique was utilized in $10 \%$ of the surveyed companies. Results also revealed that projects that used a combination of work sampling, time study, and estimating technique had no time overran concerns. Kumar, Kumar, Myneni, and Charan (2014) also found that work sampling is widely applied in the Indian construction industry to measure performance of direct work. The study by Pradeepkumar and Loganathan (2015) demonstrated the applicability of the work sampling technique in the construction industry. In this study, the researchers applied the technique on a construction projects resulting in generation of useful information regarding the productivity of the workforce. Data collected during the observation established that labor productivity at the site was above average and that nonproductive time was $36 \%$. The authors attribute the nonproductive

ECRTD-UK https://www.eajournals.org/ 
time to inadequate supervision since it was observed that the supervisors stayed on the site for a short amount of time each day. On the other hand, Goso and Imoto (2011) found that the work sampling was not widely applied in the Japanese construction industry due to absence of inventory of personal data in most organizations. They noted that an inventory of personnel data is essential in work sampling as it enables managers to track improvement in labor productivity. To solve the inventory problem, the study recommended the automation of labor productivity assessment. In their study, Josephson and Bjorkman (2013) found that work sampling is of little value in assessing productivity and analyzing performances of construction projects over time because of extreme variation in the conditions of the project.

\section{Visual Methods of Quality Assessment}

Visual assessment methods refer to a wide range of methods that rely on physical observation to judge the quality of materials, on-going work, or product (Mancill \& Thompson, 2012). One of the most common methods of visual assessment is physical inspection. Visual assessments are common in the construction industry because they are cheaper and faster to perform and facilitate immediate generation of usable information. Visual assessments can be used to evaluate materials, processes, and products/ outcomes. However, these assessments are highly subjective as judgment is made based on the assessor's competence, experiences, taste, and preferences. Their application is also limited as the can only provide information regarding surface flaws. Although it is not possible to completely eliminate bias, visual methods can be made more impartial by developing elaborate scoring systems that detail items that should be rated and procedure for developing estimates (Mancill \& Thompson, 2012). Other factors that influence the effectiveness of observational methods include the viewing distance, view duration, view activities, and planning (Hojat \& Sina, 2014). The visual methods can also be enhanced by develop a clear decisionmaking criteria to help the assessor determine the rating of each quality attribute.

\section{Feedback/ Questioning Methods}

Questioning is also a common method of assessing quality in the construction industry. This method entails asking different stakeholders to provide their views concerning specific quality issues either through interviews or questionnaires (Harrison, 2005). Today, many standardized questionnaires for assessing quality of buildings and construction projects have been developed. The Construction Owners Association of America (COAA) Questionnaire and the Building Quality Assessment (BQA) are excellent examples of such tools (Lam et al., 2006). It is also a common practice for contractor to conductor formal and informal interviews with the aim of obtaining stakeholders views regarding the quality of their processes or product. Questionnaires are often preferred because they facilitate collection of large amount of data within a short duration and at lower cost (Akbayrak, 2000). However, interviews also have their own advantages such as increased flexibility where the assessor can ask follow-up questions and seek clarification where responses are not clear (Alshenqeeti, 2014). Questioning methods are appropriate in assessing project processes, capturing quality attributes that differ from one individual to another, and examining dynamic issues. A significant disadvantage of the two methods of assessment is that there are prone to distortion of data. The respondents may not provide an accurate position of the 
actual situation due to several issues such as attribution, distorted memory, and exaggeration (Lam et al., 2006). These methods may also raise reliability issues where questions are understood differently by different respondents.

\section{Use of Records}

Another method of assessment entails the use of records. Construction projects often have a lot of documentations (Mancill \& Thompson, 2012). Some documentation can provide valuable data regarding materials, processes, and practices of the constructors. For instance, procurement records and reports can provide essential information about the quality of the materials used. Documents such as the punch list, daily activity logs, project reports, daily construction reports, and track project logs can help provide valuable information regarding the quality of workmanships (Hojat \& Sina, 2014). A major advantage of using records is that they provide an objective means of verifying performance. However, the use of records can be a cumbersome and time consuming way of assessing quality given that a given project may generates tens if not hundreds of documents. Documents are also secondary source of information; hence, the assessor cannot be absolutely certain about their accuracy.

\section{Automated Methods}

Automated methods of assessments rely on computerized tools and techniques to collect and/or analyze quality data. Today, many mechanical techniques of analysis have been developed including the use of sensors, SD laser can measurement, thermal imaging analysis, mobile robots, and infrared thermography (Liu et al., 2016). Sensors are often installed on strategic areas such as walls and floors to help collected variable data such as vibrations, sound, and heat that would help detect flaws (Abdelrazig, Chang, \& Skibniewski, 1999). For instance, a sensor can help detect structural flaw such as development of cracks by detecting sounds and vibrations that are difficult for humans to perceive.Digital imaging technologies such as SD laser and infrared thermography are often used to scan surfaces and generate data regarding their quality. Assessors can also use it to observe underlying structures such as steel reinforcement (Kalyan et al., 2016). They can also facilitate the generation of data such as thickness of floors, evenness of surfaces, verticality of walls, and hollowness of the ground (Kayan, 2016). Mechanical methods have several advantages such as high level of accuracy and multiple functionalities. However, these methods are quite expensive and the technologies involved are not readily accessible to small constructors.

\section{METHODOLOGY}

This study will employ descriptive cross-sectional case study design,this cross-sectional design is selected to understand the current situation in the Lagos construction industry with regard to quality assessment rather than test the effect or a program. The target population comprises of senior managers, project managers, technical managers, architects, quantity surveyors, and engineers working with building contractors operating the Lagos Metropolitan Area, these are selected because they are actively involved in the planning and management of construction projects; hence, they are likely to provide the information needed to answer the research questions.

ECRTD-UK https://www.eajournals.org/ 
Survey revealed that 1771 construction companies was registered in Lagos ( Public Procurement Agency, Alausa Ikeja, 2018) . 1000 construction companies are from LMA which comprises 13 local government area. The population of his study is 1000 construction companies. This study made use of the Taro Yamane sample size formulae to determine the appropriate sample size for collection of quantitative data:

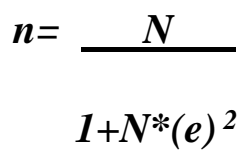

Where $\mathrm{N}=$ Population, $\mathrm{n}=$ Sample size and $\mathrm{e}=$ Margin of error

Since the unit of analysis is the building construction company, the number of registered building construction companies in Lagos Metropolitan Area will serve as population size. The population size is 1000 . The margin of error is set at $5 \%$. Using the formulae, the desired sample size would be:

$\mathrm{n}=1000 /\left[1+\left\{1000 *(0.05)^{2}\right\}\right]$

$\mathrm{n}=285.7 \approx 286$ companies.

The purposive sampling technique is adopted as it entails selecting participants based on the researcher's judgment regarding his or her ability to provide the require information. The audiorecorded Interview is the main method of data collection which took between 30 and 45 minutes depending on the level of details provided on the quality assessment methods that are currently used in their organizations, how these methods impact performance, challenges involved in implementing quality systems, and factors critical to the successful implementation of a QAS. questionnaires to 100 building construction companies operating in the Lagos Metropolitan Area. The first instrument of data collection is a semi-structured interview guide selected because of its ability to facilitate the collection of rich and contextual information, which is in line with the goal of the study while the structured questionnaires comprises of multiple choice questions to collect quantitative data via clustered random sampling method. The transcript for each interview will be analysed using t-tests to measures the impact of quality assessment system on project delivery in Lagos while the Principal Component Analysis (PCA) is used to reduce the number of variables while retaining the original variance as possible. Th method is to determine the method and approaches that the Lagos contractors are currently using to assess quality in their organizations as well as the major problem facing building contractors in applying quality assessment systems in Lagos, Nigeria. For internal validity, the researcher discussed the questions contained in the research instruments, design and method used in data collection and analysis with the experts to ensure that they capture what the study intends to measure. For external validity to enhance the generalizability of findings, the researcher documented the study methods and procedures in a clear and elaborate fashion. The reliability of the study was enhanced by conducting a pilot study

ECRTD-UK https://www.eajournals.org/ 
before the main data collection exercise. The pilot involved a total of 10 builders and utilized the test retest approach. The responses for the first and second round were compared using the Pearson Product Moment Correlation Coefficient at a threshold of 0.7. The test yielded a correlation coefficient of 0.87 leading to the conclusion that the instrument is highly reliable.

\section{RESULTS AND DISCUSSIONS}

To address the research objectives, the study sought to examine the quality assessment methods that are commonly applied in the respondent's organizations. Respondents were presented with a list of methods and ask to check all that applied. Results are presented in Table 4.0

Table 4.0: Quality Assessment Methods applied in Respondent's Organizations

\begin{tabular}{lll}
\hline Methods for Assessing Quality & N & Percent of cases \\
\hline Observation/ physical inspections & 243 & 93.1 \\
Review of records & 171 & 65.5 \\
Feedback & 144 & 55.2 \\
Sampling & 193 & 35.6 \\
\hline
\end{tabular}

Source: Field Survey, 2017

As the Table illustrates, observation/ physical inspections was the most widely applied method of quality assessment. This method entails visually assessing the workmanship and the product so as to determine whether it meets requirement. It can be viewed as a process-based method as the assessor can make the observation when work is ongoing (Mancill \& Thompson, 2012). It can also become an outcome-based method when the inspection is done after completion of specific tasks. According to Hojat and Sina (2014), the observation methods are common in the construction industry because they are easy and less costly to apply. However, these assessments are highly subjective as judgment is made based on the assessor's competence, experiences, taste, and preferences. In subsequent interview with participants, the researcher sought to establish how the constructors were applying the observation methods. All the nine respondents reported that inspections are often conducted by members of the management team. Only 3 out of the 9 interviewees reported that they often use a standard checklist during inspections. Review of records was also a popular method of quality assessment with $65.5 \%$. This method entails culling information from records such as material delivery records and receipts, punch list, daily activity logs, project reports, daily construction reports, and track project logs (Hojat \& Sina, 2014). The method is preferred by some contractors because it is less costly since it entails using information that is already available. However, this method can be very cumbersome and time consuming. It may also not provide an accurate picture regarding the quality of the construction as records can easily be falsified. About $55.2 \%$ of the respondent reported that they often use feedback from client as a method for assessing quality. This method entails soliciting feedback for various stakeholders including clients (Harrison, 2005). It is an outcome-based method as it assesses quality after the product is made. Two interviewees also reported that they often use feedback from client as a

ECRTD-UK https://www.eajournals.org/ 
method of assessing quality. Further interrogation, however, revealed that the methods used to obtain feedback are not systematic. The interviewees reported that they collect feedback from client through informal conversation rather than through the use of systematic methods such as surveys or structured interviews. Although these informal conversations generate some information regarding the quality of buildings, they may not yield comprehensive and representative views. Only $35.6 \%$ of the respondent reported the use of the sampling method of quality assessment. This is statistical method that entails studying specimen obtained from the construction project with the view of generating an understanding of the overall quality of the project (Moyo et al., 2014). The specimen may be a concrete mix or it may entail observing the workmanship of a few employees. This method guarantees the most valid results because it utilizes systematic and statistical approaches. The method is, however, complex making it difficult for typical indigenous construction companies to apply it.

The study also sought to establish the proportion of contractors who performed the quality assessment role internally vis-à-vis those that outsource this responsibility to external audit team. The majority of the respondents $(87.6 \%)$ reported that the quality assessment role in their company is done by an internal team. During the interview, it became apparent that the assessment role is mainly implemented by supervisors and senior managers within the organizations. In organizations that reported the use of the sampling technique, the interviewees reported that company engineers were mainly responsible for collecting and analyzing samples. Internal mechanisms are essential in the quality assessment process as it ensures that assessment is done in a continuous basis. Internal mechanisms can, however, fail to deliver intended outcomes when the team responsible lacks the necessarily expertise, independence, and objectivity. To eliminate such bottlenecks, it is advisable for organization to outsource the assessment role from time to time. Outsourcing quality assessment services come with significant costs (Idoro, 2011), which explains why most the organizations in Nigeria opt to stick with the internal assessment teams.

\subsection{CONCLUSION}

Developing a model for guiding the process of assessing quality among Lagos and Nigerian contractors. Based on the identified method will become the pathway for developing a framework for guiding the process of assessing quality in the construction industry. The prescribes steps, methods, tools, and procedures that local contractors should use in the assessment of quality are the core content the model will portray. The model will help to standardize the processes of assessing quality within the Lagos construction industry.

\section{ACKNOWLEDGEMENT}

Special thanks to all contributors to this research work 
British Journal of Environmental Sciences

Vol.10, No.2, pp. 41-50, 2022

Print ISSN: 2054-6351 (print),

Online ISSN: 2054-636X (online)

\section{REFRENCES}

Ajayi, O., \& Thwala, W. D. (2015). Developing an Integrated Design Model For Construction Ergonomics in Nigeria Construction Industry. African Journal of Applied Research $(A J A R), 1(1)$.

Moyo, T., Mangore, E., \& Chigara, B. (2014). Work measurement techniques utilized by the building industry in the Midlands Province of Zimbabwe. International Journal of Sustainable Construction Engineering \& Technology, 5 (1), 42- 52.

Orth, D., Welty, S., \& Jenkins, J. (2006). Analyzing labor productivity through work sampling. ASC Proceedings of the $42^{\text {nd }}$ Annual Conference. Colorado State University, U.S.A.

Josephson, P., \& Bjorkman, L. (2013). Why do work sampling studies in construction? The case of plumbing work in Scandinavia. Engineering, Construction, and Architectural Management, 20 (6), 589- 603.

Kayacan, E. (2016). Automated construction quality assessment robot system. Nayang Technological University.

Moyo, T., Mangore, E., \& Chigara, B. (2014). Work measurement techniques utilized by the building industry in the Midlands Province of Zimbabwe. International Journal of Sustainable Construction Engineering \& Technology, 5 (1), 42- 52.

AbdelRazig, Y., Chang, L., \& Skibniewski, M. (1999). Automated assessment of construction surfaces through intelligent image processing. Automation and Robotics in Construction, 3 (4), 693- 700.

Kalyan, S., Zadeh, P., Staub-French, S., \& Froese, T. (2016). Construction quality assessment using 3D as-built models generated with Project Tango. Procedia Engineering, 145 (16), 1416- 1423.

Hojjat, S., \& Sina, A. (2014). Quality and assessing quality in architectural building. Proceedings of International Conference on Architecture and Civil Engineering. Dubai, UAE.

Mancill, S., \& Thompson, M., (2012). A qualitative approach to quality assessment of facilities. Proceedings of the $48^{\text {th }}$ ASX Annual Conference

Akbayrak, B. (2000). A comparison of two data collecting methods: Interviews and questionnaires. Public Opinion Quarterly, 64 (3), 639- 642.

Alshenqeeti, H. (2014). Interviewing as a data collection method: A critical review. English Linguistic Research, 3 (1), 39-45.

Harrison, J. (2005). Construction quality assurance. Perfval White Papers. Retrieved http://perfval.com/white-papers/QA.pdf.

Lam, P., Chan, A., Wong, F., \& Wong, C. (2006). An evaluation of the need for a quality assessment scheme for private sector construction projects in Hong Kong. The International Journal of Construction Management, 6 (1), 27- 43.

Mancill, S., \& Thompson, M., (2012). A qualitative approach to quality assessment of facilities. Proceedings of the $48^{\text {th }}$ ASX Annual Conference.

ECRTD-UK https://www.eajournals.org/

Journal level DOI: https://doi.org/10.37745/bjes.2013 
Hojjat, S., \& Sina, A. (2014). Quality and assessing quality in architectural building. Proceedings of International Conference on Architecture and Civil Engineering. Dubai, UAE.

Goso, T., \& Imoto, K. (2011). Development and improvement of labor productivity assessment system in construction site using information technology. Kochi University of Technology Academic Resource Repository. Available at http://hdl.handle.net/10173/868.

Pradeepkumar, C., \& Loganathan, S. (2015). A study on minimization of construction waste through work sampling. International Journal of Science and Engineering Research, 3 (4), 235- 334.

Kumar, Y., Kumar, G., Myneni, S., \& Charan, C. (2014). Productivity analysis of small construction projects in India. Asian Journal of Applied Sciences, 7 (1), 262- 267

Mancill, S., \& Thompson, M., (2012). A qualitative approach to quality assessment of facilities. Proceedings of the $48^{\text {th }}$ ASX Annual Conference.

Harrison, J. (2005). Construction quality assurance. Perfval White Papers. Retrieved http://perfval.com/white-papers/QA.pdf.

Ashokkumar, D. (2014), Study of quality management in construction industry. International Journal of Innovative Research in Science, Engineering and Technology, 3 (1), 36- 43.

Szczerban, J. (2002). Quality assurance and quality assessment. Global Perspectives in Health, 2 (3), 363- 371.

Ahmad, H., Sabli, M., \& Othman, A. (2014). Assessing the implementation of Conquas Standard amongst contractors towards improving quality of workmanship. Jurutera, 3 (4), 25- 28.

Brown, T. A. (2015). Confirmatory factor analysis for applied research. Guilford Publications.

Dubois, A., \& Gadde, L. E. (2002). The construction industry as a loosely coupled system: implications for productivity and innovation. Construction Management \& Economics, 20(7), 621-631

ECRTD-UK https://www.eajournals.org/

Journal level DOI: https://doi.org/10.37745/bjes.2013 